\title{
Fracture healing and strength recovery in magmatic liquids
}

\author{
A. Lamur, J. E. Kendrick ${ }^{1}$, F. B. Wadsworth, Y. Lavallée
}

This file consists of supplementary information required to reproduce the work presented in the main paper.

\section{The computation of the onset time}

We use a least-squares regression technique to fit for the parameters $K$ and $\alpha$ in Eq. 1 (main text). These two parameters are mutually dependent, however, we do not explore that dependence in detail. This is valid because we do not interpret the parameters further. Nevertheless, the parameters are given here in Table DR1.

\begin{tabular}{ccccccc}
\hline Glass & $\begin{array}{c}\text { Temperature } \\
\left.\mathbf{(}^{\mathbf{C}} \mathbf{C}\right)\end{array}$ & $\begin{array}{c}\text { Viscosity } \\
(\mathbf{P a . s})\end{array}$ & $\boldsymbol{\tau}(\mathbf{s})$ & $\mathbf{K}\left(\mathbf{s}^{-\mathbf{1}}\right)$ & $\boldsymbol{\alpha}$ & $\boldsymbol{\lambda}_{\mathbf{c}}(\mathbf{s})$ \\
\hline \hline NIST & 560 & $1.27 \times 10^{10}$ & 1.27 & $1.031 \times 10^{-3}$ & 0.396 & 7.63 \\
\hline \multirow{3}{*}{ SDGS } & 590 & $1.54 \times 10^{11}$ & 15.45 & $2.684 \times 10^{-5}$ & 2.627 & 29.14 \\
& 630 & $1.56 \times 10^{10}$ & 1.56 & $1.008 \times 10^{-3}$ & 0.231 & 11.23 \\
& 645 & $7.08 \times 10^{9}$ & 0.71 & $1.546 \times 10^{-3}$ & 0.293 & 5.77 \\
\hline
\end{tabular}

Table DR1. Experimental conditions and fitting parameters for the two different glasses

We note that $\lambda_{c}$ is poorly constrained simply by extrapolating Eq. 1 (main text) to the value of $\sigma / \sigma_{0}$ where the resolution of the press is reached. Therefore, in order to compute an uncertainty on $\lambda_{c}$ we first calculate the sum of the squared residuals $R S S$, for the number of samples $N$, between the strength data points measured $X_{i}$, and the model's predictions (calculated using Eq. 1) $f\left(X_{i}\right)$ as follows

$R S S=\sum_{i=1}^{i=N}\left(X_{i}-f\left(X_{i}\right)\right)^{2}$

This is then used to calculate the standard error of estimate on strength recovery of the model, $\Gamma_{m}$ :

$\Gamma_{m}=\sqrt{\frac{R S S}{N}}$

Since at short timescales, the model overestimates the strength recovery, we can then provide the confidence interval of the model, $A$, for any strength recovery:

$A=f\left(X_{i}\right)-\Gamma_{m}$ 
We use this in Figure DR1 to find the minimum and maximum values of $\lambda_{c}$, which are, in turn, plotted as a vertical bar in Figure 1C (main text). Although not shown here, a similar result for $\lambda_{\max }$ is found if we use $\sigma / \sigma_{0}=Z \ln (t)-Q$ and extrapolate to the value of $\sigma / \sigma_{0}$ at which the press resolution is reached.
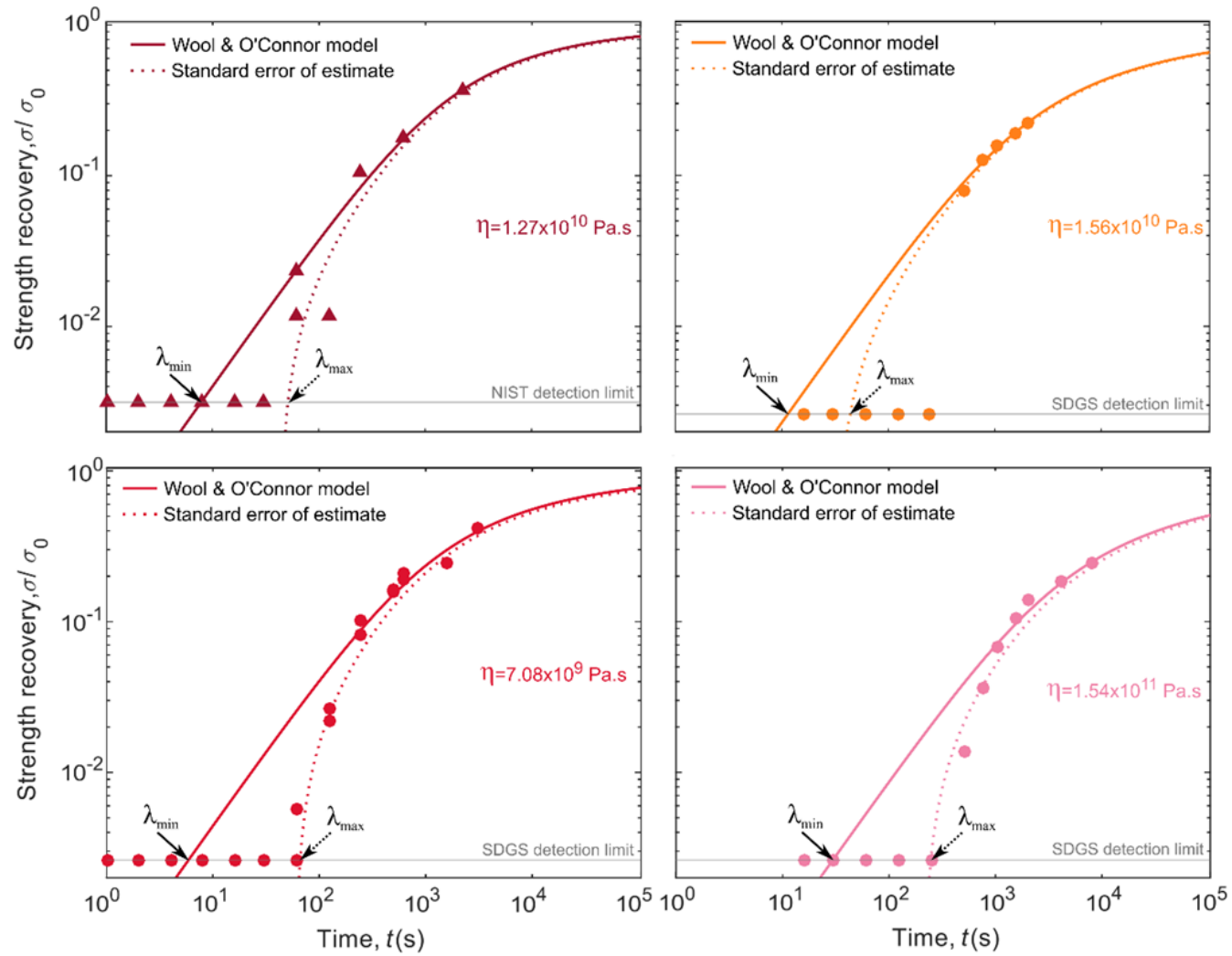

Figure DR1. Here each dataset (each sample at a temperature corresponding to a viscosity given on each panel) is plotted along with the prediction of Eq. 1 (main text; solid curve). The solid curve minus the standard error is given as the dashed curve. Both curves are used to predict the maximum and minimum $\lambda_{c}$ given in Figure $1 \mathrm{C}$ (main text), termed here $\lambda_{\max }$ and $\lambda_{\min }$, respectively. 


\section{Fracture surface geometry}

In Figure DR2, we show an image oblique to the fracture surface, showing the asperities on a typical experimental sample prior to fracture healing. This demonstrates that we are using non-smoothed fractures with asperities of approximately $2 \mu \mathrm{m}$ height.

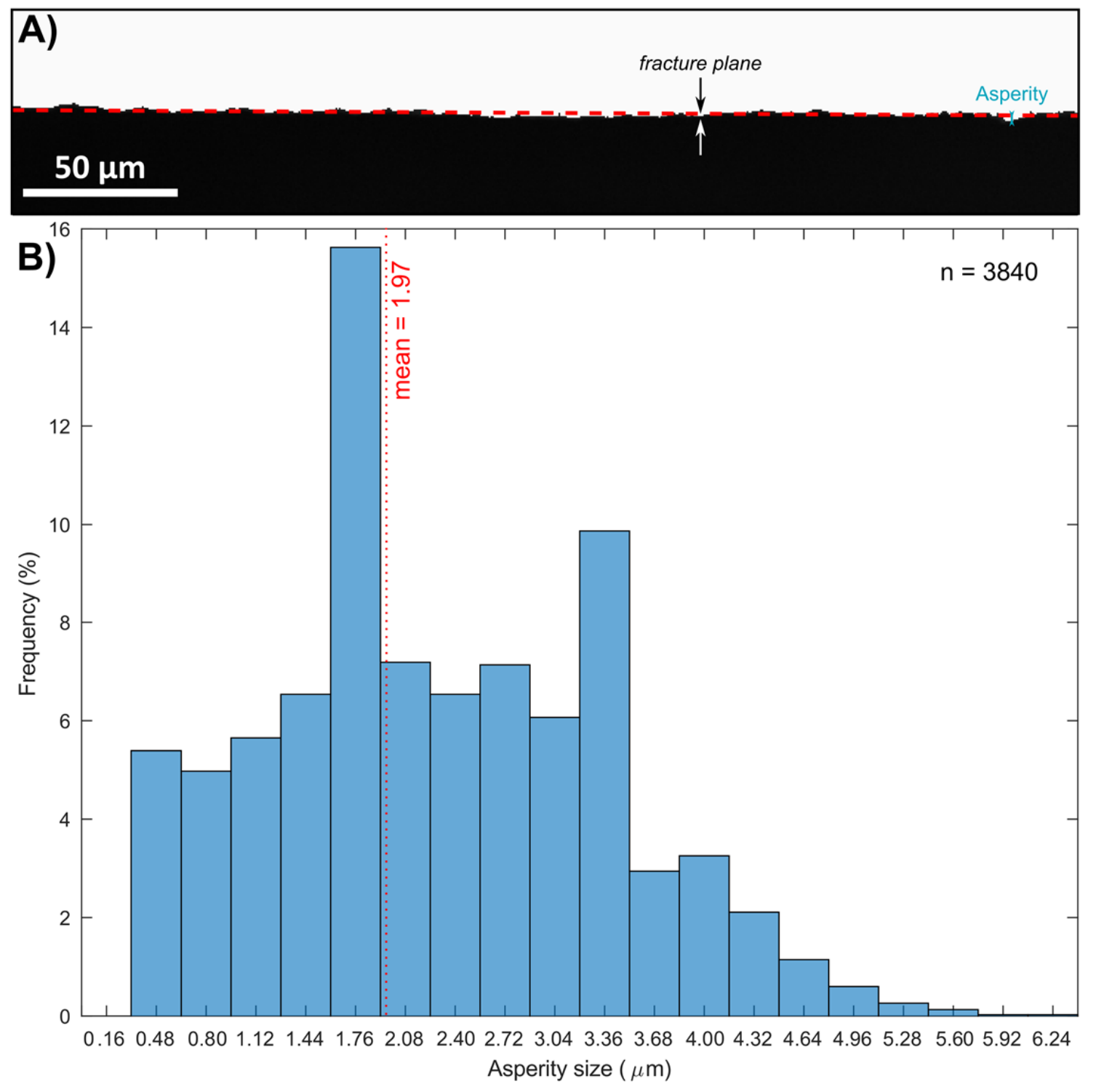

Figure DR2. Visualizing fracture surface geometries. A) Binary conversion of a backscattered electron image of a ground surface used as a synthetic fracture plane in the experiments (seen from the side); the blue arrow shows asperity size as distance from a virtual flat surface (dashed red line); B) Size distribution of 3840 asperities along a ground surface (1.05 $\mathrm{mm}$ long); the asperities range from 0.48 to $5.92 \mu \mathrm{m}(1.97 \mu \mathrm{m}$ average $)$ in size measured optically. 


\section{The evolution of contact area, used to correct the stress data}

The press records the force with time during an experiment. This needs to be converted to a stress, by dividing the surface area of contact between the two samples. However, the contact area evolves as a function of time. Therefore, using a specially designed sapphire window in the side of the furnace, we monitor the contact area and use two linear regressions as a general rule for correction (Figure DR3).

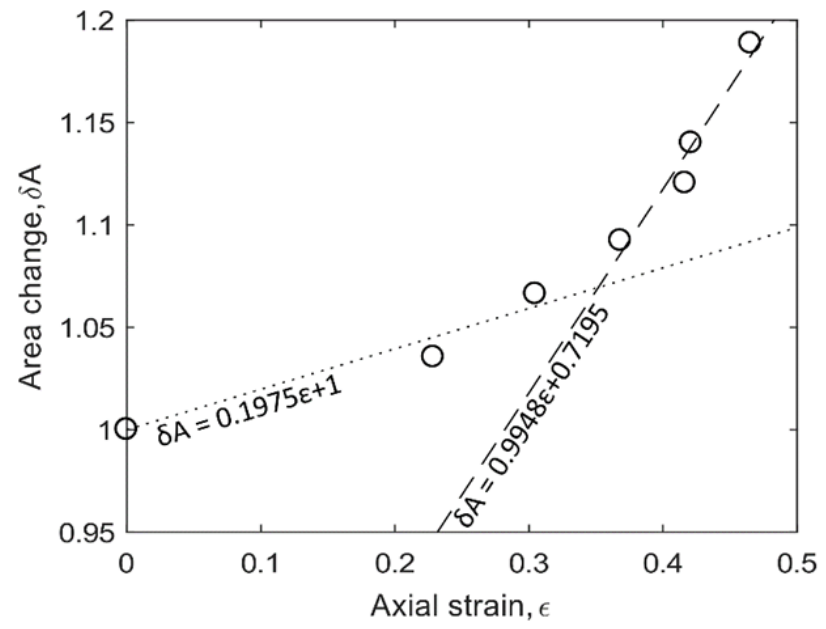

Figure DR3. Contact area evolution along the fracture plane as a function of axial strain monitored during contact of the fracture interfaces. We use two linear regressions as a general correction to these data, in order to compute stress as a function of time (or strain) in our data.

Once corrected, the relationship between axial stress and strain can be visualized (see Figure DR4 below).

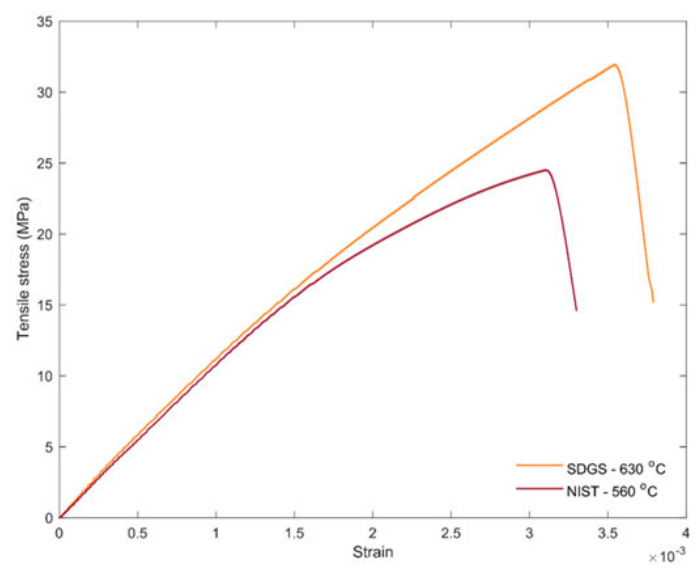

Figure DR4. Mechanical data obtained during direct pull test to measure the tensile strengths of the NIST and SDGS glasses at a viscosity of $10^{10}$ Pa.s. 


\section{The temperature dependence of viscosity of the materials used}

As an essential pre-requisite for the analysis presented in the main text, the temperature-dependence of the sample viscosity had to be determined. This is presented in Figure DR5. We used a combination of measurements from the manufacturer (from Schott GmbH for SDGS, or from NIST), and measurements on cylindrical samples following the method of Hess et al., (2008).

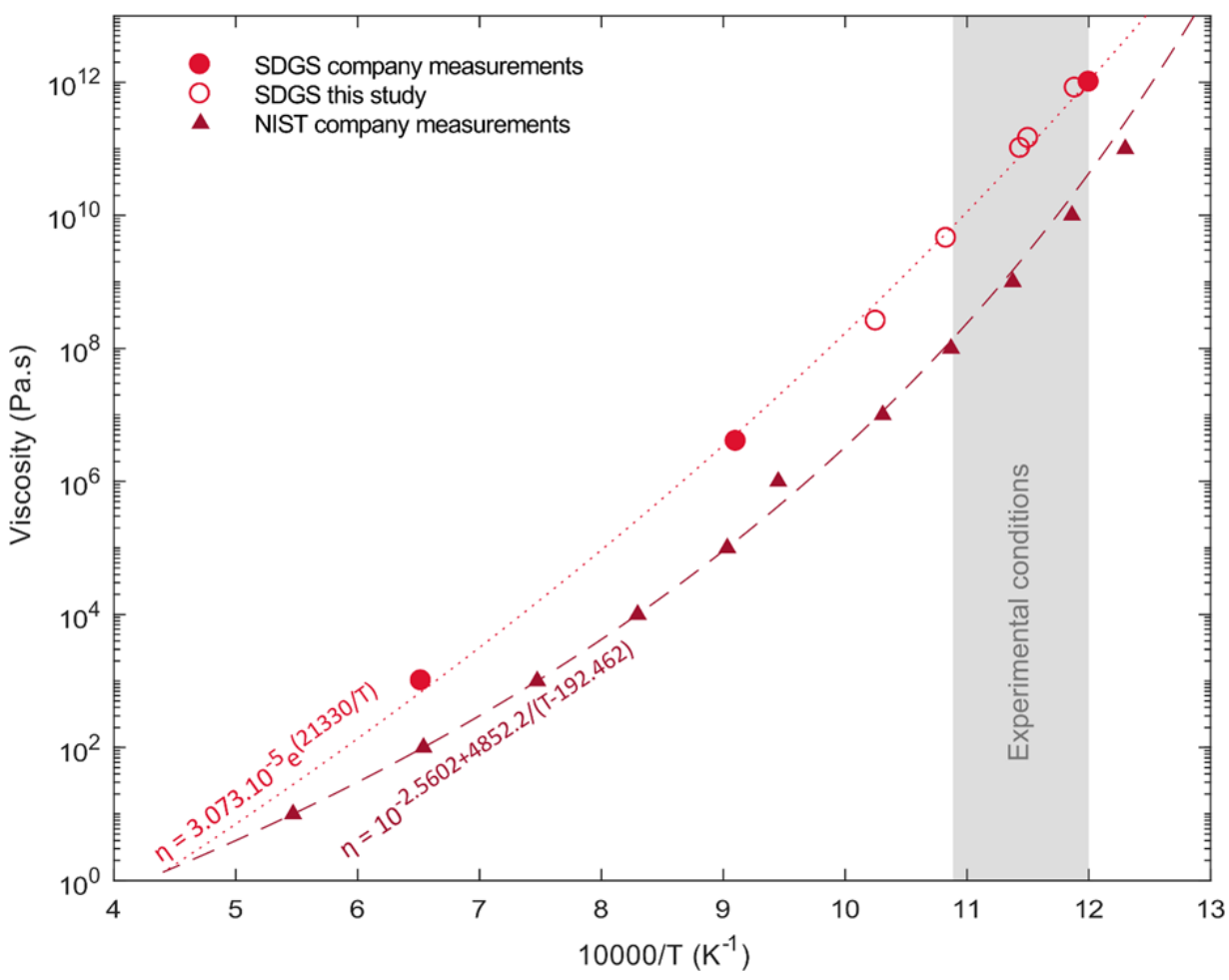

Figure DR5. Viscosity-temperature relationships for SDGS and NIST. The solid symbols show values provided by NIST (triangles) and Schott Duran ${ }^{\circledR}$ (circles). The open circles represent viscosity measurements carried out at the University of Liverpool using the parallel plate method (following Hess et al., 2008). 


\section{Raw data}

Here we provide the raw data for each sample and experimental condition.

Table DR2. SDGS strength recovery at $590^{\circ} \mathrm{C}$

\begin{tabular}{cc}
$\begin{array}{c}\text { Time of contact } \\
(\mathbf{s})\end{array}$ & $\begin{array}{c}\text { Strength recovery } \\
\left(\boldsymbol{\sigma} / \sigma_{0}\right)\end{array}$ \\
\hline \hline $\mathbf{5 0 0}$ & 0.014 \\
$\mathbf{7 5 0}$ & 0.036 \\
$\mathbf{1 0 0 0}$ & 0.067 \\
$\mathbf{1 5 0 0}$ & 0.105 \\
$\mathbf{2 0 0 0}$ & 0.138 \\
$\mathbf{4 0 0 0}$ & 0.184 \\
$\mathbf{8 0 0 0}$ & 0.244 \\
\hline
\end{tabular}

Table DR3. SDGS strength recovery at $630^{\circ} \mathrm{C}$

\begin{tabular}{cc}
$\begin{array}{c}\text { Time of contact } \\
(\mathbf{s})\end{array}$ & $\begin{array}{c}\text { Strength recovery } \\
\left(\sigma / \sigma_{\mathbf{0}}\right)\end{array}$ \\
\hline $\mathbf{5 0 0}$ & 0.079 \\
$\mathbf{7 5 0}$ & 0.126 \\
$\mathbf{1 0 0 0}$ & 0.160 \\
$\mathbf{1 5 0 0}$ & 0.189 \\
$\mathbf{2 0 0 0}$ & 0.226 \\
\hline
\end{tabular}

Table DR4. SDGS strength recovery at $645^{\circ} \mathrm{C}$

\begin{tabular}{cc}
\hline $\begin{array}{c}\text { Time of contact } \\
(\mathbf{s})\end{array}$ & $\begin{array}{c}\text { Strength recovery } \\
\left(\sigma / \sigma_{0}\right)\end{array}$ \\
\hline \hline $\mathbf{6 0}$ & 0 \\
$\mathbf{6 0}$ & 0.006 \\
$\mathbf{1 2 0}$ & 0.027 \\
$\mathbf{1 2 0}$ & 0.022 \\
$\mathbf{2 4 0}$ & 0.082 \\
$\mathbf{2 4 0}$ & 0.101 \\
$\mathbf{4 8 0}$ & 0.162 \\
$\mathbf{4 8 0}$ & 0.159 \\
$\mathbf{6 0 0}$ & 0.193 \\
$\mathbf{6 0 0}$ & 0.207 \\
$\mathbf{1 5 0 0}$ & 0.241 \\
$\mathbf{3 0 0 0}$ & 0.417 \\
\hline
\end{tabular}


Table DR5. NIST strength recovery at $560^{\circ} \mathrm{C}$

\begin{tabular}{cc}
\hline $\begin{array}{c}\text { Time of contact } \\
\text { (s) }\end{array}$ & $\begin{array}{c}\text { Strength recovery } \\
\left(\sigma / \sigma_{0}\right)\end{array}$ \\
\hline $\mathbf{6 0}$ & 0.012 \\
$\mathbf{6 0}$ & 0.023 \\
$\mathbf{1 2 0}$ & 0.012 \\
$\mathbf{2 4 0}$ & 0.104 \\
$\mathbf{6 0 0}$ & 0.177 \\
$\mathbf{2 2 0 0}$ & 0.373 \\
\hline
\end{tabular}




\section{Calculation of the conditions at Volcán Chaitén}

Castro \& Dingwell (2009) estimate the viscosity during ascent to be $10^{6}-10^{8}$ Pa.s. Given that $\tau=\mu / G_{\infty}$, and that $G_{\infty}$ is approximately $10^{10} \mathrm{~Pa}$, this results in $\tau$ of $10^{-4}-10^{-2} \mathrm{~s}$. We found that the fracture healing onset time is approximately $10 \tau$ and so the onset time is, as stated in the main text, $10^{-3}-10^{-1} \mathrm{~s}$. To find the full time for complete healing, we take the expression for the second stage of diffusive healing (given in Figure 2), and rearrange to find $1 /\left(M^{2}\right)=t_{c} / \lambda_{c}$, where $M$ is given in Figure 2 (main text) to be $1.7 \times 10^{-2}$, and $t_{c}$ is the time when $\sigma / \sigma_{0}=1$. This results in the values $t_{c}=3.5 \mathrm{~s}$ and $t_{c}=3.5 \times 10^{2} \mathrm{~s}$, as the minimum and maximum healing time, which in the main text we approximate as $10^{0}$ and $10^{2} \mathrm{~s}$, or seconds-to-minutes.

Following Castro et al. (2012), we then estimate the degassed lava to have approximate minimum dissolved water content of 0.15 wt.\%. Using the viscosity model of Hess \& Dingwell (1996) and an estimated eruptive temperature of $825^{\circ} \mathrm{C}$, we find that this results in viscosities in the range between $3.09 \times 10^{8}$ Pa.s, and $3.16 \times 10^{9}$ Pa.s. As stated in the main text, we assume these are indicative of the in-dome conditions near the surface, for which those water contents are valid. Using the method described above, this results in $t_{c}$ values of $1.07 \times 10^{3} \mathrm{~s}$ and $1.09 \times 10^{4} \mathrm{~s}$, or hours.

In the main text we use this as justification of our statement that degassed dome lavas at silicic volcanoes are likely to be far less efficient at fracture healing, than in-conduit fractures with elevated water contents, and therefore lower viscosities. 


\section{References used in this Data Repository}

Castro, J. M., \& Dingwell, D. B. (2009). Rapid ascent of rhyolitic magma at Chaitén volcano, Chile. Nature, 461(7265), 780.

Castro, J. M., Cordonnier, B., Tuffen, H., Tobin, M. J., Puskar, L., Martin, M. C., \& Bechtel, H. A. (2012). The role of melt-fracture degassing in defusing explosive rhyolite eruptions at volcán Chaitén. Earth and Planetary Science Letters, 333, 63-69.

Hess, K. U., \& Dingwell, D. D. (1996). Viscosities of hydrous leucogranitic melts: A nonArrhenian model. American Mineralogist, 81(9-10), 1297-1300.

Hess, K.-U., Cordonnier, B., Lavallée, Y., and Dingwell, D. B., 2008, Viscous heating in rhyolite: An in situ experimental determination: Earth and Planetary Science Letters, v. 275, no. 1-2, p. 121-126. 